\title{
Working
}

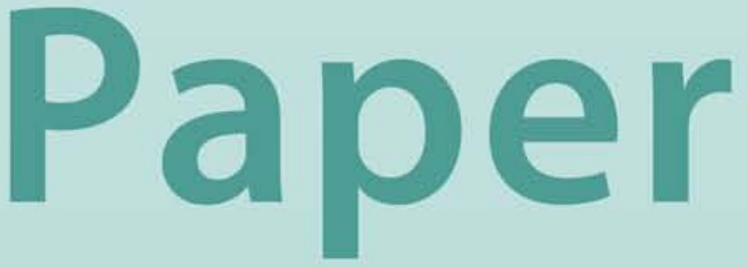


Catch-Up Growth, Habits, Oil Depletion, and Fiscal Policy:

Lessons from the Republic of Congo

Stéphane Carcillo, Daniel Leigh, and

Mauricio Villafuerte 


\title{
IMF Working Paper
}

Fiscal Affairs Department

\section{Catch-Up Growth, Habits, Oil Depletion, and Fiscal Policy: Lessons from the Republic of Congo}

Prepared by Stéphane Carcillo, Daniel Leigh, and Mauricio Villafuerte

Authorized for distribution by Manmohan Kumar, Rolando Ossowski, and Gerd Schwartz

April 2007

\begin{abstract}
This Working Paper should not be reported as representing the views of the IMF. The views expressed in this Working Paper are those of the author(s) and do not necessarily represent those of the IMF or IMF policy. Working Papers describe research in progress by the author(s) and are published to elicit comments and to further debate.
\end{abstract}

In a number of oil producing countries, oil revenue accounts for the majority of government revenue, but is expected to be depleted in a relatively short time frame. Ensuring that fiscal policy is on a sustainable path is thus a high priority, but political and social adjustment costs create incentives to delay fiscal consolidation. This paper estimates how the permanently sustainable non-oil primary deficit (PSNOPD) depends on the speed of consolidation, using an optimization model with habit formation. Realism is added by allowing for negative growth-adjusted interest rates during a temporary period of catch-up growth. Applied to the Republic of Congo, this approach leads to the following conclusions: (i) the current fiscalpolicy stance is unsustainable; (ii) social adjustment costs justify spreading the bulk of the adjustment over five years; and (iii) the slower the adjustment, the lower the PSNOPD level.

JEL Classification Numbers:E6, H5, Q3

Keywords: Sustainable fiscal policy, habit formation, permanent-income hypothesis, catch-up growth, oil, Republic of Congo.

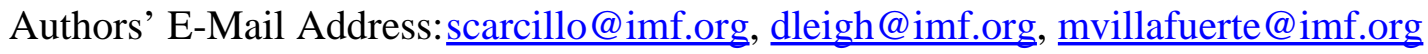


I. Introduction

II. Background

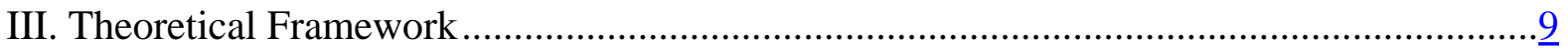

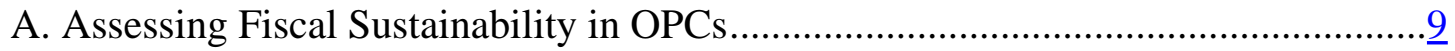

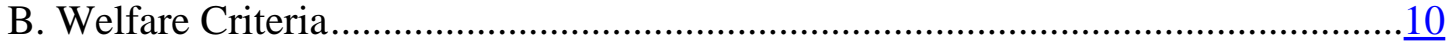

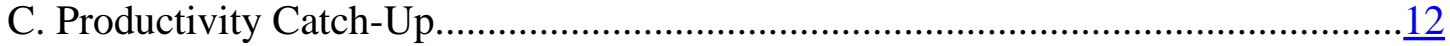

D. Adjustment Costs .................................................................................. $\frac{13}{13}$

E. A Formal Model ................................................................................... $\frac{13}{16}$

F. Model Calibration for Congo..................................................................

IV. Results and Sensitivity Tests .............................................................................18

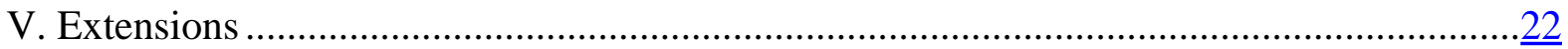

A. Uncertainty and Precautionary Saving Motives...............................................22

B. Productive Capital Spending ....................................................................

C. Public Expenditure Management Issues …................................................

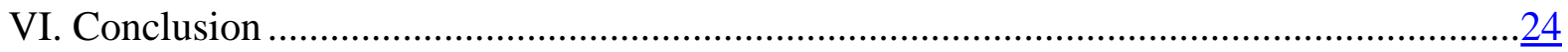

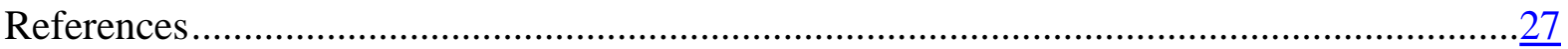

Tables

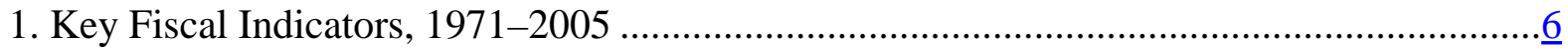

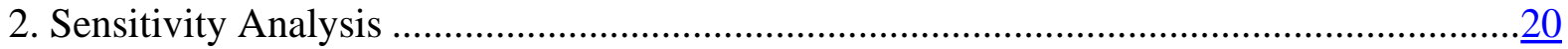

Figures

1. Oil Production in Congo and National Oil Price, 1990-2006 ............................................ $\underline{5}$

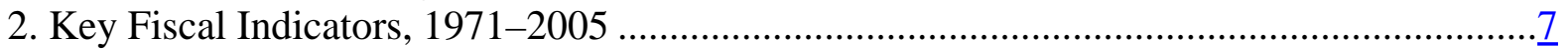

3. Human Development Index and Growth .................................................................. $\frac{8}{8}$

4. Oil Production and National Oil Price Outlook, Assumptions for 2006-60 ......................18

5. Fiscal Adjustment Path (Baseline Assumptions), 2005-60 .............................................21

6. Adjustment Towards the Permanently Sustainable Non-Oil Primary Balance Under

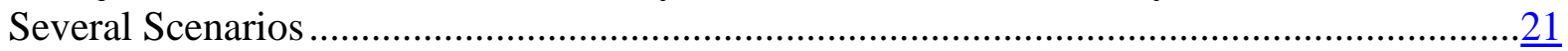

7. Tradeoff Between Adjustment Speed and Estimated PSNOPD .........................................22

8. Primary Expenditure and Non-Oil Primary Balance in billion CFAF Using Two Different

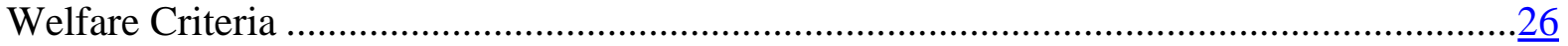

9. Primary Expenditure and Non-Oil Primary Balance as a percentage of NOGDP Using

Different Welfare Criteria.........................................................................................26

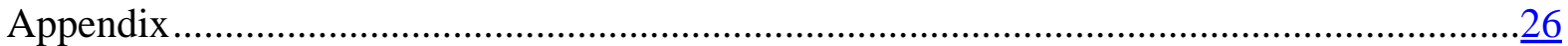




\section{INTRODUCTION}

In a number of oil producing countries (OPCs), oil revenue accounts for the majority of all government revenue, but oil reserves are expected to be depleted within 30 years. Ensuring that fiscal policy is on a sustainable path is therefore a high priority. At the same time, political and social adjustment costs create incentives to delay fiscal consolidation. The volatility of commodity prices makes it particularly important that such countries pay attention to the debt dynamics of fiscal policy over the medium and long term. An important challenge is thus to strike the right balance between spending now and saving for the future when natural resources will be depleted.

This paper analyses how the permanently sustainable non-oil primary deficit (PSNOPD) depends on the speed of fiscal adjustment, using an intertemporal optimization model with adjustment costs in the form of habit formation. A key operational advantage of the model is that it allows for temporarily negative growth-adjusted (real) interest rates during a period of rapid catch-up growth. The paper features a discussion on the methodological aspects of assessing fiscal sustainability in OPCs. Notably, a caveat of this model is that it abstracts from the possible impact of (additional) public (human and physical) capital expenditure on assumed long-run growth rates, fiscal non-oil revenue, and fiscal sustainability. However, given the lack of robust evidence regarding the relationship between public investment and growth, evaluating fiscal sustainability without allowing for productive public investment provides a useful benchmark.

This approach is applied to the Republic of Congo (hereafter "Congo"), where oil reserves are expected to be depleted by 2050. Congo’s economic history since the 1970s illustrates the dangers of following a procyclical fiscal policy in a heavily oil-dependent economy, and not saving a sufficiently large share of current oil revenues to ensure the sustainability of fiscal policy in the medium- and long-run. The limited success of many oil-producing countries in using their oil resources wisely to improve living standards for the average citizen, including Congo's experience in the 1980s, also highlight the need to adopt a comprehensive mediumterm fiscal strategy.

In estimating the PSNOPD for Congo, the paper reaches three main conclusions. First, Congo's current fiscal-policy stance is unsustainable. The non-oil primary deficit (NOPD) in 2005, at 29 percent of non-oil GDP (NOGDP) ${ }^{1}$, is well above the estimated PSNOPD of 10 percent. This assessment is robust to a number of sensitivity tests, including a more optimistic oil-price and oil-production outlook. Second, the presence of social adjustment costs justifies spreading the bulk of the adjustment toward the sustainable level over five years. Such a phased consolidation is assessed as optimal in this model, and differs substantially from the one-time abrupt adjustment to the PSNOPD level prescribed by traditional permanent income hypothesis $(\mathrm{PIH})$ models without habit formation or other adjustment costs. Finally, there is a trade-off between the speed of adjustment and the level

\footnotetext{
${ }^{1}$ The non-oil primary deficit is defined here as the difference between non-oil revenues, including grants, and total primary expenditures.
} 
of the long-run PSNOPD. For example, taking 20 years to complete 60 percent of the adjustment - compared to 5 years in the baseline scenario-reduces the PSNOPD from 12 percent to 5 percent of non-oil GDP.

The remainder of the paper is structured as follows: Section II provides background on fiscal performance and oil production in Congo. Section III describes the analytical framework and calibrates the model to fit Congo's economy. On that basis, Section IV estimates the permanently sustainable fiscal deficit and simulates the optimal adjustment path toward this level. Section V discusses further considerations, including reforms aimed at improving the quality of public spending. Section VI summarizes the results and concludes.

\section{BACKGROUND}

Congo began developing its oil sector in the late 1950s. This sector is today the country's primary source of economic growth. Congo was the sixth largest oil producer in 2005 in subSaharan Africa, after Nigeria, Angola, Sudan, Equatorial Guinea, and Gabon. The country is heavily dependent on its oil sector, which accounts for about half its GDP and more than 80 percent of government revenues and merchandise exports.

According to the 2006 estimates by the Oil and Gas Journal (OGJ), Congo has 1.5 billion barrels of proven oil reserves, most of which are located offshore. One of the more recent oil discoveries in 2004 was the onshore M'Boundi field with proven reserves of 250 million barrels. Based on geological data, undiscovered reserves are estimated at 5.8 billion barrels on a risk-weighted basis. Congo's crude oil types are typically medium and sweet.

Oil production in Congo commenced in 1957 from the onshore Pointe Indienne field, which reached a peak output of about 2,500 barrels per day in the mid-1960s. During the 1980s and 1990s, Congo's crude production quadrupled, from 65,000 barrels per day in 1980 to an average of 280,000 barrels per day in 2000 (Figure 1). Since then, production has been falling, largely due to a decline in production at mature fields and delays in bringing several new fields online. Crude oil production fell from an average of 275,000 barrels per day in 2001 to 254,000 barrels per day in 2005. However, oil production is expected to rebound over the medium term as new fields (including the M'Boundi field onshore, and the MohoBilondo field offshore starting from 2008) come online and offset declining output at more mature fields. Approximately 35 to 50 percent of the oil production goes directly to the government and is mostly sold by the national oil company, the SNPC, on the state's behalf. The rest goes to the international oil partners, based on bilateral oil sharing contracts.

Congo's economic history since the 1970s illustrates the dangers, in terms of macroeconomic stability, of following a procyclical fiscal policy in a heavily oil-dependent economy. The oil boom of the 1970s and early 1980s encouraged the Congolese authorities to adopt in 1981 an ambitious Five-Year Economic and Social Development Plan, underlying which was an expansionary fiscal policy path (Table 1, Figure 2). Government investment rose by an average annual rate of 15 percent in the first half of the 1980s. Even though current expenditure was curtailed, the domestic financial imbalances, which had widened in the second half of the 1970s, continued to deteriorate in the first half of the 1980s. In addition, the country's external indebtedness, which had already grown rapidly in the 1970s and early 
1980s to finance domestic investment, doubled between 1980-84 and 1985-89, and led to an unsustainable debt path.

Figure 1. Oil Production in Congo and National Oil Price, 1990-2006
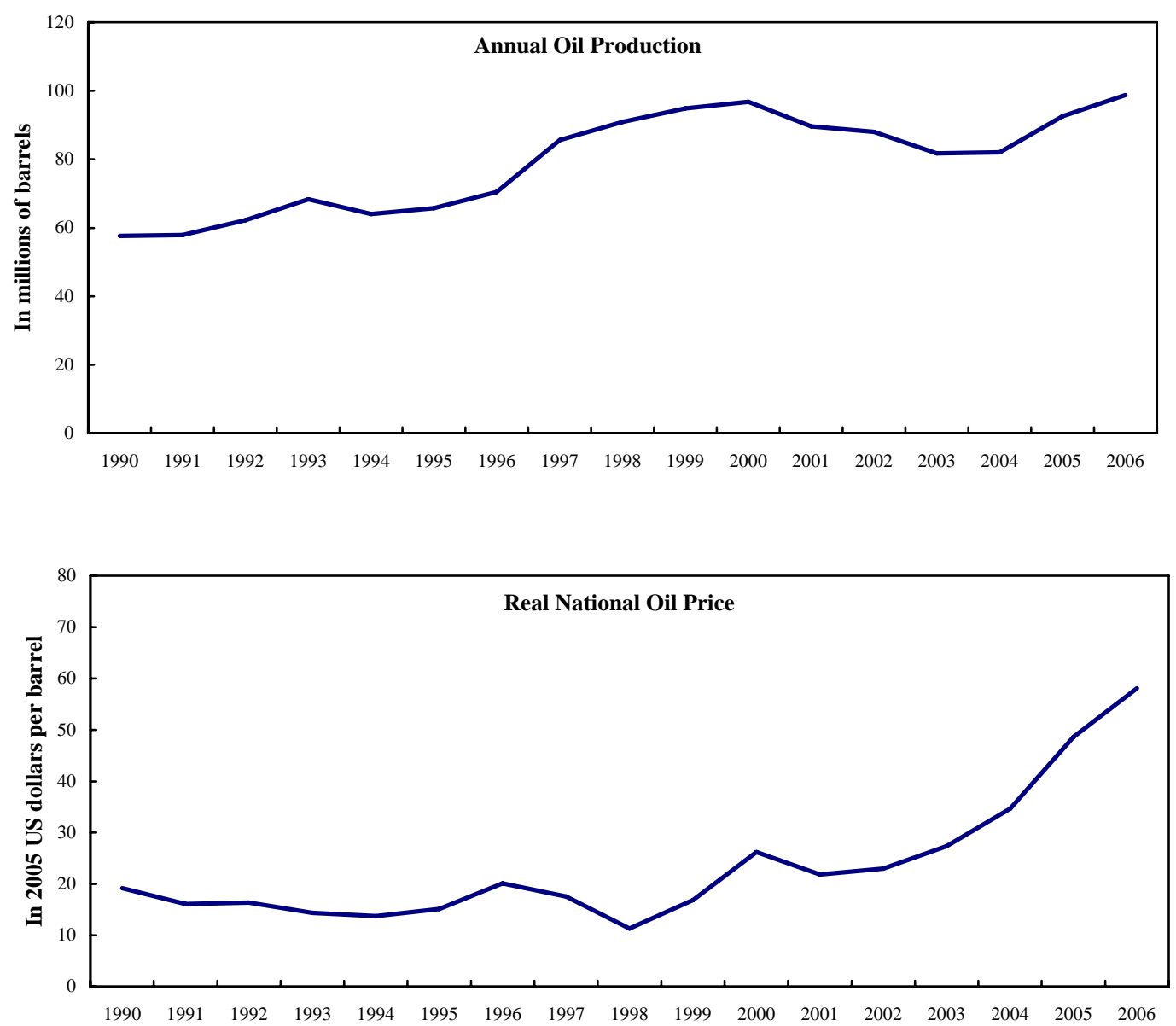

Sources: Congolese authorities, IMF staff calculations.

The rapid rise of the public sector during the oil boom years of the early 1980s, including in the form of large public employment creation, partly provided the seeds for the subsequent long decline in output. The oil bonanza came to an end in the second half of the 1980s, when oil prices declined to an average of \$18 per barrel during 1986-90 (from an average of $\$ 31$ per barrel during 1981-85). In view of the associated significant decline in oil revenues, the government undertook some fiscal adjustment measures, some within the context of an IMF Stand-By Arrangement launched in August 1986. However, the government's policy response to the terms of trade shock in the second half of the 1980s was slow and limited, relying mainly on cuts in government investment spending and limited structural reforms. As a result, economic activity stagnated, fiscal and external imbalances widened markedly, and the external public debt and debt-service burdens grew to unsustainable levels. In addition, large domestic and external payment arrears accumulated. 
Table 1. Key Fiscal Indicators, 1971-2005

(In percent of GDP, unless otherwise indicated)

\begin{tabular}{lrrrrrrr}
\hline & $1971-1975$ & $1976-1980$ & $1981-1985$ & $1986-1990$ & $1991-1995$ & $1996-2000$ & $2001-2005$ \\
\hline Oil revenues & & & & & & & \\
Primary current expenditures & 4.4 & 9.3 & 22.1 & 11.5 & 12.7 & 17.9 & 23.2 \\
Capital expenditures & 23.2 & 26.9 & 22.9 & 23.2 & 25.8 & 23.8 & 23.3 \\
Primary balance & 4.7 & 5.3 & 20.4 & 4.9 & 1.8 & 6.8 & 7.5 \\
Overall balance (including grants) & -0.8 & -0.7 & 12.1 & 1.4 & -2.2 & 4.7 & 9.3 \\
Public and publicly guaranteed external debt & -4.8 & -6.4 & -6.7 & -10.3 & -12.3 & -8.8 & 2.3 \\
Memorandum item: & 41.2 & 64.6 & 86.7 & 150.7 & 194.1 & 217.9 & 178.6 \\
$\quad$ Oil price (US\$ per barrel) & & & & & & & \\
\hline
\end{tabular}

The fiscal imbalances of the late 1980s were followed by a large devaluation and a significant decline in per capita GDP. Given the magnitude of the macroeconomic imbalances in the late 1980s and early 1990s, it became clear by 1993 that fiscal adjustment alone would not be sufficient to restore external competitiveness because nominal domestic prices showed considerable downward rigidity. In addition, the onset of civil war in Congo in 1993-94 further complicated macroeconomic management. The CFA franc was devalued by 50 percent in January 1994 to restore competitiveness and boost exports. As a result, per capita GDP declined from its peak of US\$1,390 in 1984 to about US\$980 in 1995 (both in constant 2000 U.S. dollars), resulting in a large increase in the incidence of poverty (see below). Over the following decade, successive economic programs supported by the IMF went off track, owing to further political instability, weak fiscal discipline, and insufficient resolve to implement structural reforms, especially in the oil sector.

In summary, Congo's lack of a strategy to manage fiscal oil revenue in the 1980s including considerations to preserve the nation's oil wealth resulted in unsustainable growth, and an eventual sharp decline in living standards. Even though Congo's human development index is higher than the average for sub-Saharan Africa and for (oil- and non-oil producing) PRGF-eligible countries, it has been falling steadily since 1985 (Figure 3). Moreover, poverty remains widespread: a recent household survey, completed in early 2006, shows that 42 percent of households and 51 percent of individuals live below the poverty line, and that pockets of poverty are equally distributed in urban and rural areas. Over the past decade Congo has also fallen significantly behind other developing countries, including oil-producing PRGF-eligible countries, in per capita GDP growth performance. 
Figure 2. Key Fiscal Indicators, 1971-2005

(In percent of GDP)
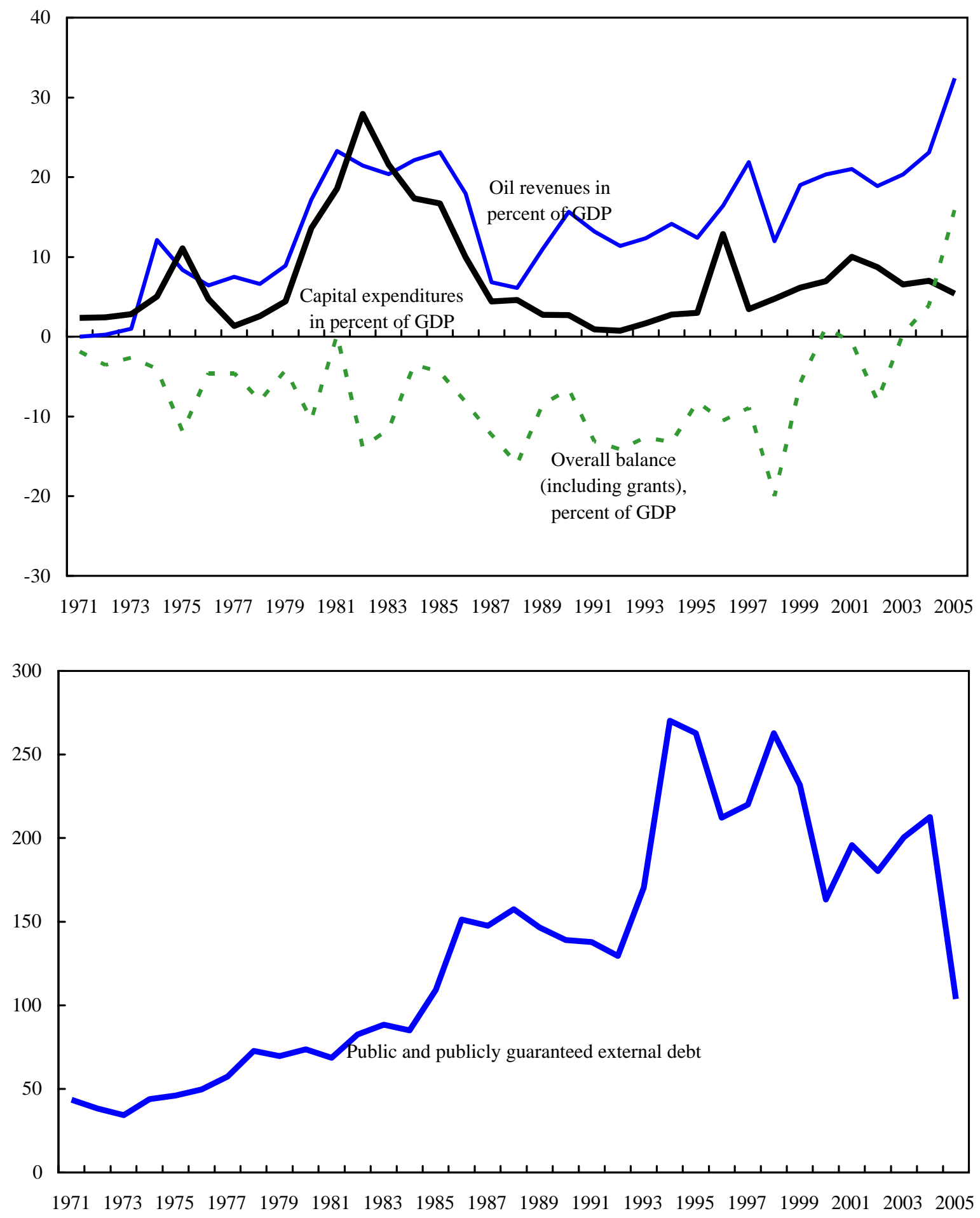

Sources: Congolese authorities, IMF staff estimates, and World Development Indicators. 
Figure 3. Human Development Index and Growth
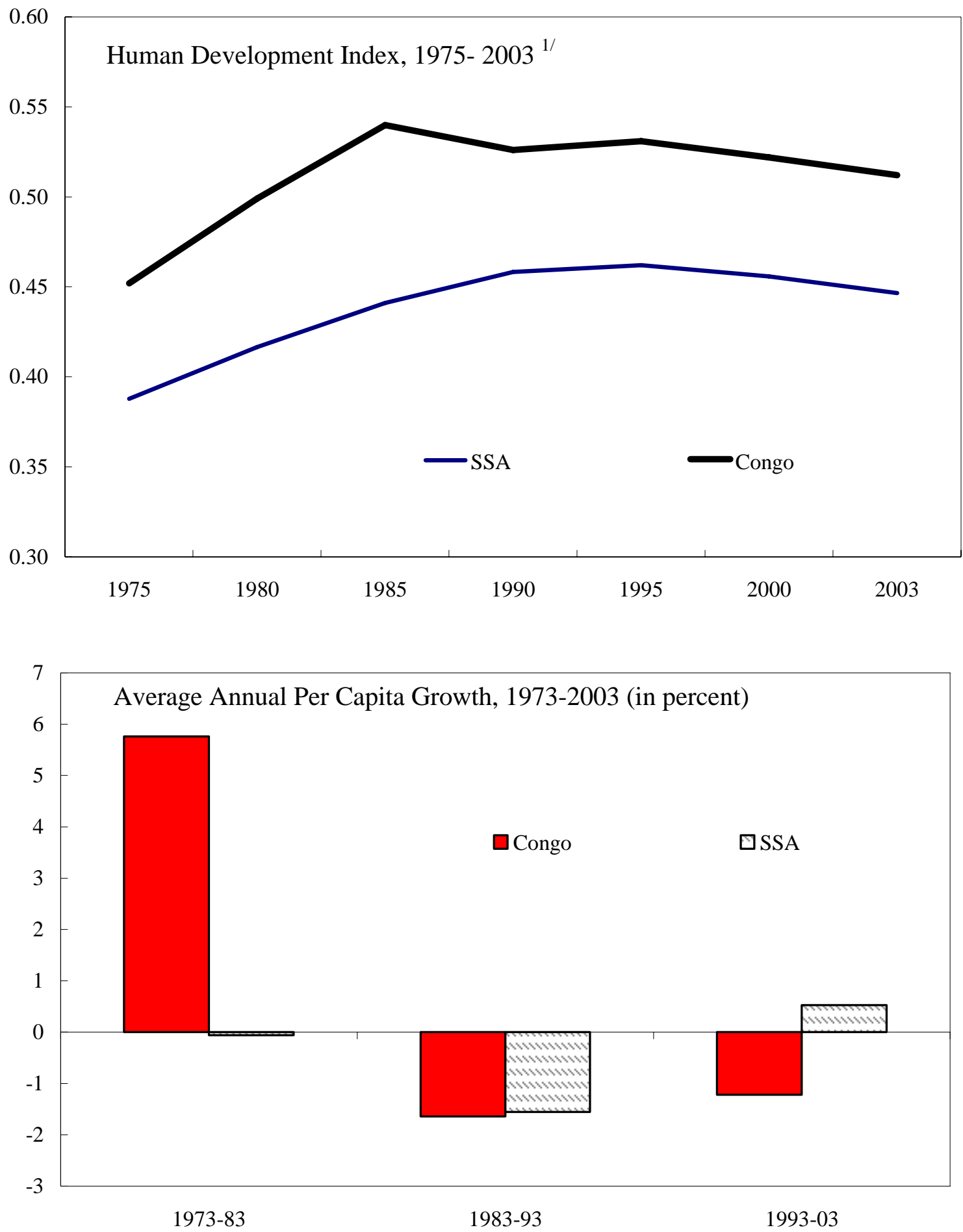

Sources: IMF, World Economic Outlook, and United Nations Development Program.

1/ Includes only countries for which data are available for all periods. 
The limited success of many oil-producing countries in using their oil resources wisely to improve living standards-including Congo's experience in the 1980s-highlight the need for adopting a comprehensive medium-term fiscal strategy. The experience of Nigeria is striking in this regard. Sala-i-Martin and Subramanian (2003) conclude that all the oil revenue over the period from 1965 to 2000 had almost no impact on the standard of living of the average Nigerian. ${ }^{2}$ They attribute this waste of the nation's oil wealth to weak institutions, corruption, and poor public expenditure management-including the use of oil revenues to finance "white elephant" projects, such as the building of the famous Ajakouta steel complex in the 1970s, which to this day has not produced a single commercial ton of steel. A key objective of any comprehensive medium-term fiscal strategy in an oil producing country, such as Congo, must surely be to minimize the chances of this type of waste of the nation's oil resources from occurring in the future. Another equally important objective should be to prevent a macroeconomic crisis from occurring once fiscal oil revenues start declining, requiring deep and painful cuts in government spending and a fall in living standards.

\section{THEORETICAL FRAMEWORK}

\section{A. Assessing Fiscal Sustainability in OPCs}

Analyses of public debt sustainability commonly rely on medium-term projections of the debt-to-GDP ratio given macroeconomic forecasts and fiscal policy assumptions. While such projections do not determine per se the sustainability of a particular public debt position, the expected debt path provides some indication as to whether the underlying policies can be sustained under plausible macroeconomic conditions without endangering government solvency. A projected decline in the debt ratio is typically interpreted as a signal that government policies do not jeopardize sustainability, whereas a positive trend or even stabilization at a level that exceeds an indicative threshold level (such as 60 percent of GDP) typically raises concerns about sustainability.

For oil-producing countries (OPCs) with large but exhaustible oil resources, it is appropriate for the analysis to incorporate the following three considerations. First, the projection period should be extended beyond the typical horizon used for debt-sustainability analysis (DSA) for advanced industrial and emerging market economies (generally 5 to 10 years) and even for low income countries (20 years). In particular, it is important to consider whether, under plausible macroeconomic conditions, the net debt (or assets)-to-GDP ratio is expected to stabilize at a level that can be maintained indefinitely after oil resources are exhausted. Second, the exhaustible nature of oil resources raises important inter-generational distributional issues, and the analysis of debt sustainability should evaluate these

\footnotetext{
${ }^{2}$ Sala-i-Martin and Subramanian (2003) calculate that, over the period 1965 to 2000, Nigeria's cumulative net revenues from oil amounted to about US\$350 billion at 1995 prices. In 1965, when oil revenues per capita were about US\$33, per capita GDP was US\$245. In 2000, when oil revenues per capita were US\$325, per capita GDP remained at the 1965 level.
} 
inter-generational equity issues using an explicit criterion. An accepted approach to incorporating these equity considerations is to analyze fiscal policy using models based on the $\mathrm{PIH} .{ }^{3}$ Third, in assessing the sustainability of the current fiscal stance, it is appropriate to focus on the non-oil primary fiscal balance (that is, non-oil revenue excluding interest receipts minus non-oil non-interest expenditure). In fact, when oil is depleted the NOPB will become the primary balance. The non-oil primary balance provides a clearer indicator of the fiscal policy stance for OPCs because it filters out fluctuations in revenue due to swings in international oil prices, and thus provides a more accurate assessment of the underlying stance of fiscal policy. ${ }^{4}$

The analysis that follows incorporates these three considerations. A key oil variable is net oil wealth, defined as the present discounted value of future net oil revenue. In line with standard analyses of public debt sustainability, this paper does not include measures of public physical and human capital in the definition of net government wealth. Nor does it explicitly consider the potential impact of public investments (in physical and human capital) on long-run growth. Here, public investment is essentially not different from public consumption as the rate of medium and long-run growth is not endogenous to the composition and level of public spending, but rather chosen exogenously. We discuss the implications of this important assumption in the last section.

In this framework, a challenge for fiscal policy is deciding how to allocate net government wealth (i.e., net financial assets plus net oil wealth) across generations. This challenge, reflecting a concern for intergenerational equity, should be met by targeting a fiscal policy that explicitly takes into account the projected evolution of net government wealth. Finally, and analogously to the standard PIH arguments, the preservation of net government wealth would require that consumption in each period be limited to permanent income or, in this case, the implicit return on government wealth. Formally, the optimal fiscal policy is defined as the path of non-oil revenue and primary government spending that maximizes the government's social welfare function. The focus of the analysis can be simplified by focusing on the non-oil primary deficit-which is ultimately what governs the transfer of resources between periods — rather than the specific non-oil tax-and-spending mixture.

\section{B. Welfare Criteria}

In addressing intergenerational equity considerations using the $\mathrm{PIH}$, a number of welfare criteria are possible. Welfare criteria are typically expressed in terms of a weighted sum of current and future generations' utilities. As such, analyzing social welfare requires making an assumption regarding (i) the rate of time preference ("impatience"), that is, how much to

\footnotetext{
${ }^{3}$ Standard DSA addresses intergenerational equity considerations indirectly, by implicitly recommending a stabilization of public debt in percent of GDP at a "prudent" level. Such a recommendation has implications for the distribution of the responsibility to reimburse public debt across generations.

${ }^{4}$ As oil revenue is exhausted, the non-oil primary fiscal balance converges towards the overall primary balance used in traditional DSA analyses.
} 
discount the utility of future generations; and (ii) the period utility function, that is, what society derives utility from out of government spending in any given time period. Regarding the rate of time preference, the standard approach is to assume a rate that is consistent with smoothing spending over time and avoiding excessive spending in the short run at the expense of future generations. However, for political-economy reasons, governments may in fact exhibit a higher degree of "impatience." ${ }^{5}$ While the rate of time preference is ultimately a question of political or social preference, the following analysis is based on a degree of patience that permits smoothing of spending over time. ${ }^{6}$

Regarding the period utility function, the following three specifications are possible:

(i) Real-terms criterion. Here, utility in any given time period is derived from aggregate government consumption in real terms. Under standard assumptions, this criterion would imply a constant path of government spending in real terms out of net government wealth. However, assuming a positive rate of NOGDP growth, this criterion would also imply the need for a continuous adjustment in the NOPD in percent of NOGDP towards zero.

(ii) Real per capita criterion. Here, utility in any given time period is derived from government consumption per capita. This criterion would be more restrictive for fiscal policy than the first one (assuming positive population growth), as it would, under standard assumptions, require the government to save a sufficient proportion of net government wealth to permit the real level of spending to grow in line with population growth. While accumulating such a higher stock of financial assets would permit a higher real level of spending in the long term than under criterion (i), it would, in the short term, require a lower level of real spending. As in approach (i), this approach would also imply the need for a continuous reduction of the NOPD in percent of NOGDP (if population were lower than non-oil growth), albeit slower than in (i).

(iii) Share of NOGDP criterion. Here, utility in any given time period depends on the size of government spending in percent of NOGDP (equivalent to total GDP following the depletion of oil). Under standard assumptions, this approach would involve maintaining net government wealth constant in percent of GDP in the long run (as in the standard DSA analysis). The approach would also involve accumulating a higher stock of financial assets than under approach (ii), to permit real spending to growth at the rate of NOGDP growth. Assuming real per-capita NOGDP growth, this criterion would allow government spending in the long run to surpass the level achieved under

\footnotetext{
${ }^{5}$ In addition, it may be optimal for the government of a developing country to spend a large part of national oil wealth upfront if public investment delivers high positive externalities for growth (see Section VI for a discussion). However, under such circumstances, the issue would become one of optimal portfolio allocation, and not necessarily one of time preference.

${ }^{6}$ Achieving a smooth profile for spending is consistent with the degree of impatience being equal to the real rate of interest, as discussed by, for example, Obstfeld and Rogoff (1996), and Blanchard and Fischer (1998).
} 
criterion (ii), but would, in the short term, require a lower level of spending. Also, unlike approaches (i) and (ii), applying this criterion would allow the NOPD to be constant in percent of NOGDP.

While there is no accepted consensus on which utility function to apply, the following considerations can guide the choice of criterion. First, while formulating budgetary policy on a per-capita basis (criterion ii) could be rationalized on theoretical grounds (optimal consumption analyses often assume a utility function that depends on real consumption per capita, i.e., the consumption level of a representative agent), it is often less convenient for budget-formulation purposes than expressing fiscal targets in real terms (criterion i) or in percent of GDP (criterion iii). Second, applying option (i) would imply that government expenditure out of net government wealth on a per capita basis and as a share of NOGDP would necessarily tend towards zero over time (assuming positive NOGDP and population growth, see Appendix). Such a declining path of spending in per capita terms would favor current generations at the expense of future generations. Overall, the share-of-NOGDP criterion (iii) is often more convenient for budget-formulation purposes than using a per-capita criterion, and is consistent with other studies on fiscal sustainability in OPCs. ${ }^{7}$

Based on the discussion above, this paper uses the share-of-NOGDP welfare criterion in determining the sustainable fiscal path for Congo, with some adjustments as explained in the next two sections.

\section{Productivity Catch-Up}

In using the share-of-NOGDP criterion, the analysis in this paper allows for the realistic possibility of negative growth-adjusted (real) interest rates during a temporary period of rapid catch-up growth. This approach differs from a number of studies based on the same welfare criterion that assume that the real interest is always larger than the growth rate. Given that a number of lower-income OPCs are currently experiencing high non-oil growth in excess of real interest rates, it is important to incorporate this feature into the analysis. Strong non-oil growth can arise in post-conflict situations, as in the case of Congo, or in periods of productivity catch-up during which a relatively poor country converges towards the income levels of its richer trade partners. For present purposes, the reasons underlying the high non-oil growth are not as important as the possibility that it could, at least in the short- to medium-run, exceed the real interest rate.

Assuming that real interest rates are lower than non-oil growth on a permanent basis would need to be clearly justified and reconciled with arbitrage and other theoretical considerations. If the long-run growth-adjusted real interest rate is negative on a permanent basis, then this solves trivially any debt problem. However, in the case of a creditor, such as an OPC that has transformed oil wealth into a stock of financial wealth, it implies that the creditor's stock of net financial assets will converge towards zero as a share of NOGDP. A constant NOPD as a

\footnotetext{
${ }^{7}$ For example, this welfare function is used in a fiscal sustainability analysis for Gabon by Leigh and Olters (2006).
} 
ratio of NOGDP thus becomes unsustainable as the ratio of investment income to NOGDP that finances that deficit shrinks continuously, forcing continuous NOPD adjustment (as a ratio of NOGDP).

Assuming that real interest rates are lower than non-oil growth on a temporary basis will have an impact on the adjustment path towards a sustainable NOPD. A temporarily negative growth-adjusted real interest rate reduces the incentive to save, due to the substitution effect, other things equal. This substitution effect tilts the path of the non-oil primary balance upwards, due to higher spending in the short run. In addition, there is an income effect. Future oil revenue in percent of NOGDP is lower when NOGDP is expected to reach higher levels. This lower future oil-related income in percent of NOGDP would, other things equal, shift the entire profile of the non-oil primary balance in percent of NOGDP towards zero. Overall, the path of the NOPD in percent of NOGDP would decline during the period in which growth exceeds the real interest rate, with the NOPD stabilizing once the period of faster growth has ended at a level that is lower than without the faster non-oil growth. This result is formally derived in subsection $\mathrm{E}$.

\section{Adjustment Costs}

Introducing adjustment costs into the model has the advantage of greater realism with regard to the speed at which fiscal policy can adjust to the targeted NOPD position. Habit formation, developed in the consumption literature to capture the idea that consumption is addictive, provides one way of modeling adjustment costs. ${ }^{8}$ In the context of fiscal policy, habit formation can also be interpreted as reflecting institutional and political adjustment costs faced by policymakers (for instance, cutting the public-sector wage bill abruptly may not be politically feasible). Applying habit formation to fiscal policy, Velculescu (2004) shows that the optimal fiscal response to a permanent negative shock is to spread the necessary policy adjustment over a number of periods. Leigh and Olters (2006) introduce habit formation into the analysis of fiscal sustainability in the case of Gabon.

\section{E. A Formal Model}

The government's optimization problem can be solved in a two stage process: (i) an intertemporal decision (determining the size of the primary deficit); and (ii) an intratemporal decision (determining the allocation of the given deficit between spending and taxes, that is, where the marginal benefit of spending equals the marginal cost of taxation). ${ }^{9}$ Allowing the government to choose both the non-oil tax rate and the non-oil spending level is equivalent to rewriting the problem in terms of the non-oil primary deficit. The government's problem is as follows: ${ }^{10}$

\footnotetext{
${ }^{8}$ Habit formation implies that the amount of utility derived from consumption today depends negatively on how much was consumed in previous periods.

${ }^{9}$ See Barnett and Ossowski (2003).

10 The notation here follows Barnett and Ossowski (2003).
} 


$$
\begin{gathered}
\max _{\left\{G_{s}\right\}} \sum_{s=t}^{\infty} \beta^{s-t} \cdot U\left(G_{s}\right), \\
\text { s.t. } \quad B_{t}=R_{t} \cdot B_{t-1}+G_{t}-T_{t}-Z_{t}, \text { and } \\
\lim _{s \rightarrow \infty} R_{t}^{-s} B_{t+s}=0,
\end{gathered}
$$

where $B_{t}$ is government debt at the end of period $t ; R_{t}=1+r_{t}$, with $r_{t}$ being the current interest rate (assumed to be constant); and $G_{t}$ the level of primary government expenditure. Non-oil revenue is denoted by $T_{t}$, oil revenue by $Z_{t}$. The discount factor is $\beta=(1+\delta)^{-1}<1$, where $\delta$ is the rate of time preference (the degree of impatience). The government's objective is to maximize social welfare due to government spending in current and future periods, Equation (1), subject to a period budget constraint, Equation (2), and a no-Ponzi game condition, Equation (3). It is assumed that there is no uncertainty about the future.

First, a solution is obtained based on the assumption of constant non-oil GDP. The government's problem yields a solution in the form of the following Euler equation:

$$
U^{G}\left(G_{t}\right)=\beta \cdot R_{t+1} \cdot U^{G}\left(G_{t+1}\right)
$$

where $U^{G}\left(G_{t}\right)$ denotes the marginal utility of spending in period $t$. Assuming for the time being that $\beta \cdot R_{t+1}=1$, it follows that $U^{G}\left(G_{t}\right)=U^{G}\left(G_{t+1}\right)$. This implies that government spending is constant: $G_{t}=G_{t+1}=G$. Combining equation (4) with (2) and (3), and assuming $\log$ utility, $U\left(G_{t}\right)=\ln \left(G_{t}\right)$, yields the optimal level of government spending:

$$
G_{t}=\frac{r}{R} \cdot\left(Z_{t}+\sum_{j=1}^{N} \prod_{i=1}^{j} \frac{1}{R_{t+i}} Z_{t+j}+T+\sum_{j=1}^{\infty} \prod_{i=1}^{j} \frac{1}{R_{t+i}} T_{t+j}-R_{t} \cdot B_{t-1}\right),
$$

where $N$ is the date at which oil revenue runs out. Equation (4) implies that the optimal policy is to set spending equal to permanent income, i.e., to the return on the present discounted value of all future oil and non-oil revenues, and on the current stock of net financial assets.

Introducing non-oil growth does not change the essential form of the solution. NOGDP is now assumed to grow at rate $\gamma_{t}>0$, i.e., $Y_{t+1}=\left(1+\gamma_{t}\right) \cdot Y_{t}$. Following Barnett and Ossowski (2003) and Tersman (1991), the government's problem is expressed in terms of NOGDP. Therefore, $g=\frac{G}{Y}$ is the ratio of spending to NOGDP, and the budget constraint becomes

$$
b_{t}=\frac{R_{t}}{1+\gamma_{t}} \cdot b_{t-1}+g_{t}-\tau_{t}-z_{t}
$$


where $\tau$ denotes the ratio of non-oil revenue to NOGDP, and $z$ and $b$ the ratios to NOGDP of oil revenue and debt, respectively. To simplify the analysis, utility is also expressed in terms of NOGDP, so that $U=U(g)$. While the standard assumption that the interest rate, $r$, is higher than the non-oil growth rate, $\gamma$, applies in the long run $(r>\gamma)$, it is possible, for reasons discussed in Section III.C, for the growth rate to exceed the interest rate in the nearto medium-term $r_{t}<\gamma_{t}$.

Solving the model with non-oil growth implies a path for government spending that is equal to permanent income, as in equation (5), except that it is expressed in terms of NOGDP:

$$
g_{t}=\frac{r-\gamma}{R} \cdot\left(z_{t}+\sum_{j=1}^{N} \prod_{i=1}^{j} \frac{1+\gamma_{t+i}}{R_{t+i}} \cdot z_{t+j}+\tau_{t}+\sum_{j=1}^{\infty} \prod_{i=1}^{j} \frac{1+\gamma_{t+i}}{R_{t+i}} \cdot \tau_{t+j}-\frac{R_{t}}{1+\gamma_{t}} \cdot b_{t-1}\right) \text {. }
$$

Assuming a constant non-oil tax ratio $\tau_{t}=\tau$, and that both the interest rate and growth rate have reached their long-run constant values ( $r$ and $\gamma$, respectively), this equation provides a constant value of spending as a percentage of NOGDP. The permanently sustainable non-oil primary deficit (PSNOPD) is then constant at $g-\tau$.

The impact of a temporarily negative growth-adjusted real interest rate is easiest to see by looking at the first-order conditions in the model expressed in terms of NOGDP. In particular, if the growth-adjusted interest rate is negative, then the following first-order condition applies:

$$
U^{g}\left(g_{t}\right)=\beta \cdot \tilde{R_{t+1}} \cdot U^{g}\left(g_{t+1}\right)
$$

where: $g_{t}$ is government spending in percent of NOGDP; the discount factor is adjusted such that $\beta=\frac{1+\gamma}{1+r}$ where $r$ is the long-run interest rate and $\gamma$ is the long-run growth rate (such that $\beta<1$ ); and $\tilde{R}_{t}=\frac{1+r_{t}}{1+\gamma+\gamma_{t} *}$, and $\gamma_{t}^{*}$ is the excess of the temporarily high growth over the long-run growth rate $\gamma$ for some time (such that $\gamma_{t}{ }^{*}>0$ ). Since $\tilde{R}_{t}<R$, where $R$ is now the long-run growth-adjusted interest rate factor $\left(R=\frac{1+r}{1+\gamma}\right)$ then it must be the case that $\tilde{\beta R_{t}}<1$, and therefore $g_{t+1}<g_{t}$. This indicates that the NOPD, at least while growth is at the temporarily high level $\left(\gamma+\gamma_{t}^{*}\right)$, is steadily declining as a share of NOGDP. Once growth returns to its long-run level $(\gamma)$, the solution is identical to that of equation (6) and the NOPD is constant in percent of NOGDP. The path of government spending therefore implies a gradually decreasing NOPD until the growth converges to its long-run level.

Introducing habit formation into the model has the advantage of greater realism with regard to the speed at which fiscal policy can adjust to macroeconomic shocks. Formally, 
introducing habits implies altering the utility function so that current-period utility depends not only on current spending, but also on past spending. Specifically, the utility function becomes $U\left(g_{t}, h_{t}\right)$ rather than $U\left(g_{t}\right)$, where $h_{t}$ represent the current stock of habits. Solving the government's problem yields Euler equation:

$$
U^{g}\left(g_{t}, h_{t}\right)+U^{h}\left(g_{t+1}, h_{t+1}\right)=\tilde{R_{t+1}} \cdot \beta \cdot\left[U^{g}\left(g_{t+1}, h_{t+1}\right)+\beta \cdot U^{h}\left(g_{t+2}, h_{t+2}\right)\right]
$$

where $U^{g}\left(g_{t}, h_{t}\right)$ denotes the marginal utility of an additional unit of spending in this period and $U^{h}\left(g_{t+1}, h_{t+1}\right)$ the marginal utility of stronger habits in the next period (due to higher spending today). A popular formulation of habit formation in the literature is the "subtractive formulation":

$$
U\left(g_{t}, h_{t}\right)=V\left(g_{t}-\alpha \cdot h_{t}\right)
$$

where $\alpha \in[0,1]$ denotes habit strength, and current-period spending, $g_{t}$, yields lower utility the stronger the habits, $h_{t}$. A simple specification of the habit stock is $h_{t}=g_{t-1}$, i.e., the current habit stock is simply equal to the level of spending in the previous period. Combining the Euler equation (9) with the intertemporal budget equation yields, after a number of algebraic manipulations, the following optimal path for government spending:

$$
g_{t}=\left(1-\phi_{t}\right) \cdot \frac{r-\gamma}{R} \cdot\left(z_{t}+\sum_{j=1}^{N} \prod_{i=1}^{j} \frac{1+\gamma_{t+i}}{R_{t+i}} \cdot z_{t+j}+\tau_{t}+\sum_{j=1}^{\infty} \prod_{i=1}^{j} \frac{1+\gamma_{t+i}}{R_{t+i}} \cdot \tau_{t+j}-\frac{R_{t}}{1+\gamma_{t}} \cdot b_{t-1}\right)+\phi_{t} g_{t-1} \text {, }
$$

where $\phi_{t}=\frac{\alpha\left(1+\gamma_{t}\right)}{R_{t}}$. Equation (11) shows that, with habit formation, spending is a linear combination of the last period's level and the permanent income level. The implication is if the previous period's NOPD is higher than the permanently sustainable level, then it is expected to adjust to the permanently sustainable level over a number of periods. In contrast, without habits $(\alpha=0)$, the optimal policy would be to adjust abruptly to the permanently sustainable level in a single period.

\section{F. Model Calibration for Congo}

To simulate a baseline path for adjusting fiscal policy a over the medium term, this subsection calibrates the model to fit the relevant features of Congo's economy. Once a baseline scenario is simulated, sensitivity tests are conducted on all the parameters of the model. To establish the baseline projection for future real oil revenue requires projections for the real oil price and the volume of oil production. The baseline projection for oil prices is based on the February 2007 World Economic Outlook (WEO) projections for 2007-12, according to the oil price is expected to average US\$64.3/bbl over the 2008-12 period. In the longer-run we assume the later value will hold as a baseline (US\$63.3/bbl). Two alternative 
price paths, under which real oil prices either decline to US $\$ 43.3 / \mathrm{bbl}$ by 2030 or increase to US\$83.3/bbl are also considered (Figure 4).

As for future oil output, we consider Congo has proven oil reserves of at least 2 billion barrels. In the absence of further discoveries, annual oil production is expected to decline from its current level by about one-half in twenty years and to be exhausted in about thirty years (also Figure 4). Multiplying the predicted production volumes by the real price path, net of the intermediate consumption (which is assumed to remain a constant part of revenue, at the 2005 level) produces a forecast for real oil GDP. These calculations includes a discount for Congo crude oil relative to the Brent crude price, which is about 20 percent and increases to 23 percent in the long-run. In addition, the government tax take (oil revenue to oil GDP) is dependent of the level of the Brent price, and varies between 39 percent (at low price levels such those experience in 2000-02) and 53 percent (at high price levels such those experience in 2006). The paper assumes that the long-run oil tax rate will be 47 percent in the baseline scenario, 41 percent in the low price scenario, and 53 percent in the high price scenario.

Exchange rate forecasts are based on the same WEO projections of the U.S. dollar euro rate for 2006-12, implying a gradual appreciation from CFAF 527 per US\$1 in 2005 to CFAF 483 in 2012; afterwards, the exchange rate is held constant at CFAF 483 per US\$1. The non-oil tax rate is kept constant at the 2005 level of 18 percent. It is also assumed that the long-run real interest rate equals 4 percent, below the current 4.4 percent paid on debt which is supposed to hold for another five years (2006-11). The non-oil growth rate, $\gamma$, is set at 2 percent in the long-run, below the current $6 \frac{1}{2}$ percent which reflects a catch-up period, and is supposed to hold during 2006-11, and decline to its long-run level over the following five years. The habit-strength parameter, $\alpha$, is set at 0.7 , which is within the range of estimates in the literature. ${ }^{11}$ Table 2 summarizes the assumptions underpinning the baseline simulation.

\footnotetext{
${ }^{11}$ For estimates of the habit formation parameter, see Fuhrer (2000) and Gruber (2001).
} 
Figure 4. Oil Production and National Oil Price Outlook, Assumptions for 2006-60
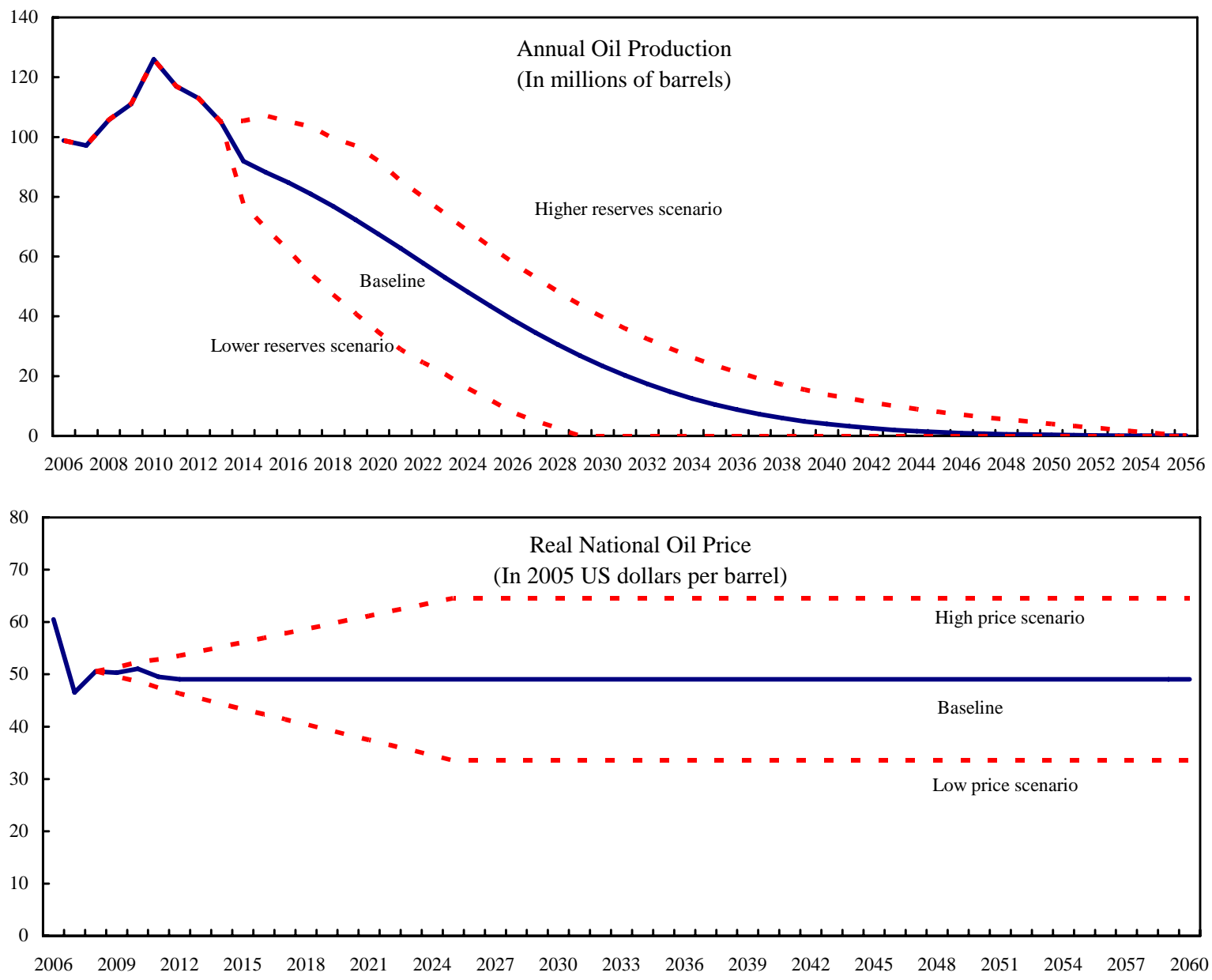

Sources: Congolese authorities, IMF staff estimates.

\section{Results AND SENSITIVITy Tests}

In simulating the optimal adjustment path, starting from the 2005 non-oil primary deficit level of 29 percent of NOGDP, three main results emerge:

First, the current level of the non-oil primary deficit is not sustainable. If the non-oil primary deficit is maintained at the 2005 level of 29 percent of non-oil GDP, debt will eventually explode. With baseline assumptions, the permanently sustainable non-oil primary deficit is estimated to be about 13 percent of non-oil GDP (Figure 5). The result that the 2005 deficit is unsustainable is robust, even under the most favorable assumptions, based on a range of sensitivity tests on all the parameters in the model (Table 2). For example, even if total reserves were to increase by 30 percent relative to the baseline, the sustainable deficit would rise to 16 percent of non-oil GDP, still well below the actual 2005 level. If the authorities succeeded in raising the tax take on oil GDP by 5 percentage points under the baseline assumptions, the sustainable non-oil primary deficit would increase to 15 percent of non-oil 
GDP, also well below the 2005 level of 29 percent of NOGDP. Figure 6 reports the baseline estimate of the PSNOPD, as well as a band that measures the uncertainty of the results (i.e., the best and worst-case scenarios considered in Table 2). ${ }^{12}$

Second, the optimal path involves spreading the bulk of the adjustment over a period of five years. Under baseline parameters, the non-oil deficit would decline by 9 percentage points to 20 percent of non-oil GDP by 2011, which would be close to 60 percent of the total adjustment required. Figure 4 shows that substantial overall primary surpluses occur during the oil period — needed to pay off debt and accumulate sufficient financial assets. From a fraction of the returns on those assets, it then finances the non-oil deficit in the post-oil period. By contrast, a strategy of stabilizing net debt at a positive level would not be consistent with running a permanent deficit in the post-oil era. As oil reserves are exhausted, the primary surpluses decline and converge to the permanently sustainable level of 13 percent of GDP in 2026, some years before oil revenue is assumed to dry up.

Third, the level of the PSNOPD depends on the speed of adjustment. Figure 7 shows how the estimated PSNOPD varies for different speeds of adjustment. For example, while the baseline scenario is consistent with completing more than 60 percent of the adjustment within 5 years, extending this period to 20 years would halve the PSNOPD to only 8 percent of NOGDP.

${ }^{12}$ Adopting a real-terms welfare criterion instead of a share of NOGDP criterion would imply significantly larger levels of primary expenditure and non oil primary deficit in the short to medium term, but would also require a much larger adjustment in the long term (see Figures 7 and 8 in Appendix). Indeed, adopting a realterms criterion leads to a constant absolute size of the government (in real CFAF) that would be larger in the short and medium run than that obtained under the share of NOGDP criterion, but lower in the long run. Besides, the size of the government would be continuously declining to zero relative to NOGDP. Consequently, the NOPD would first increase (and reach a larger level than under the share of NOGDP criterion), but then decrease in terms of percent of NOGDP. 
Table 2. Sensitivity Analysis

Optimal permanently sustainable non-oil primary deficit (in percent of annual non-oil GDP)

\begin{tabular}{|c|c|}
\hline Scenario & Result \\
\hline Baseline parameters & 13.4 \\
\hline \multicolumn{2}{|l|}{ Sensitivity tests } \\
\hline \multicolumn{2}{|c|}{ Long-run Brent oil price * (baseline $=$ US $\$ 61 / \mathrm{bbl})$} \\
\hline Higher oil prices (US\$80/bbl) & 18.1 \\
\hline Lower oil price (US\$40/bbl) & 10.3 \\
\hline \multicolumn{2}{|l|}{ Oil reserves (baseline $=100$ ) } \\
\hline Higher oil reserves (130) & 16.0 \\
\hline Lower oil reserves $(70)$ & 8.9 \\
\hline \multicolumn{2}{|l|}{ Effective oil tax take (baseline $=47 \%$ ) } \\
\hline Higher oil tax take $(+5 \mathrm{ppt})$ & 15.0 \\
\hline Lower oil tax take (-5 ppt) & 11.7 \\
\hline \multicolumn{2}{|c|}{ Long-run interest rate ${ }^{* *}$ (baseline: $r=4.0$ ) } \\
\hline Higher $r=4.5$ & 16.0 \\
\hline Lower $r=3.5$ & 10.3 \\
\hline \multicolumn{2}{|c|}{ Long-run growth rate $* *$ (baseline: $\gamma=2.0$ ) } \\
\hline Higher $\gamma=2.5$ & 10.0 \\
\hline Lower $\gamma=1.5$ & 16.7 \\
\hline \multicolumn{2}{|l|}{ Habit strength (baseline: $\alpha=0.7$ ) } \\
\hline No habits $(\alpha=0)$ & 14.0 \\
\hline Stronger habits $(\alpha=0.8)$ & 12.8 \\
\hline Weaker habits $(\alpha=0.6)$ & 13.6 \\
\hline
\end{tabular}

Source: IMF staff simulations

Notes: $\left(^{*}\right)$ National oil price is lower due to quality discount Long-run values hold for years 2016 onwards. 
Figure 5. Fiscal Adjustment Path (Baseline Assumptions), 2005-60

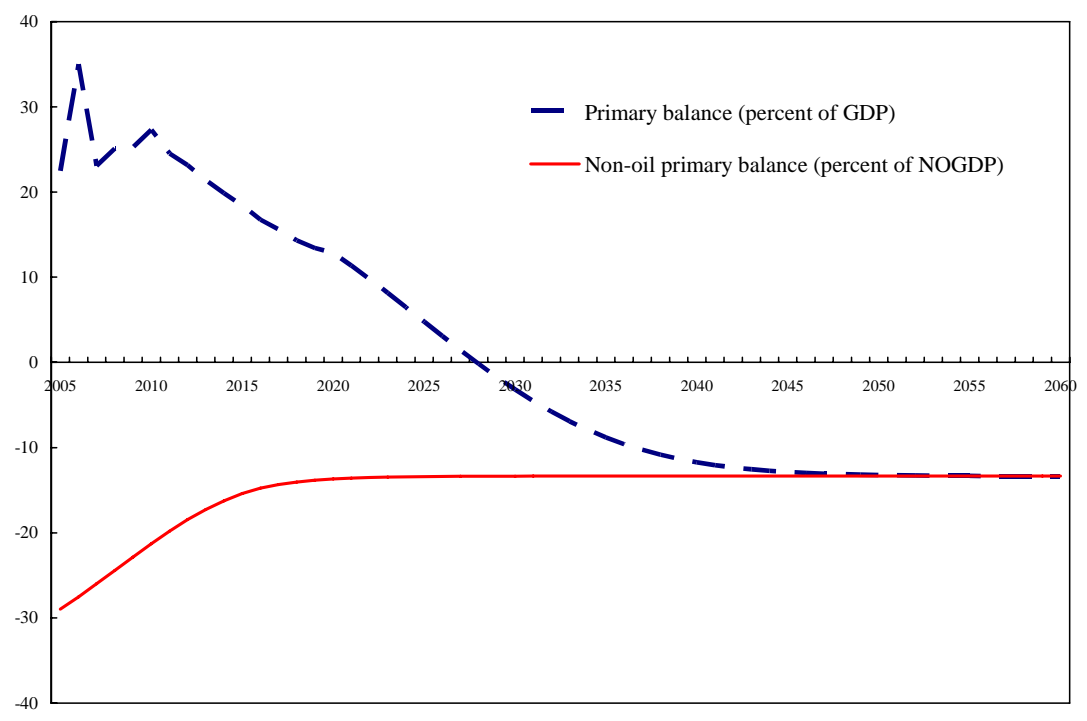

Source: IMF staff simulations.

Figure 6. Adjustment Towards the Permanently Sustainable Non-Oil Primary Balance Under Several Scenarios ${ }^{13}$

(In percent of NOGDP)

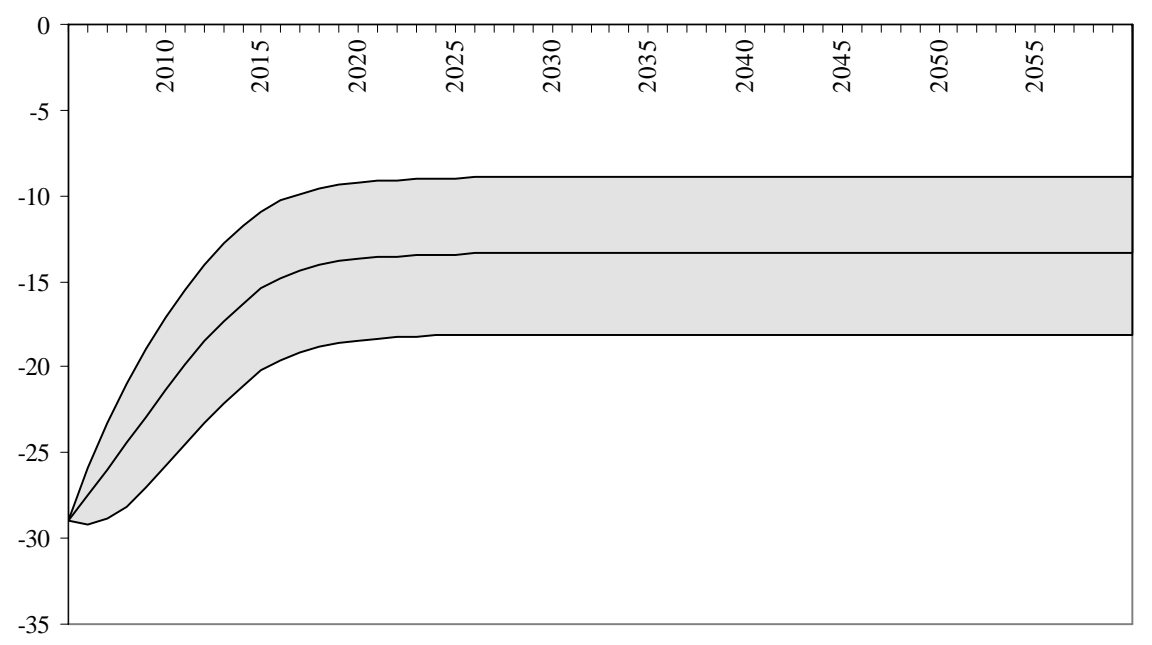

Source: IMF staff simulations.

${ }^{13}$ The Figure reports baseline estimate, as well as band measuring uncertainty of the results. The varying values of the parameters are those shown in Table 2. An Excel file that replicates all the simulation results presented in the paper is available upon request and can readily be adapted and applied to other countries with exhaustible energy resources. 
Figure 7. Tradeoff Between Adjustment Speed and Estimated PSNOPD

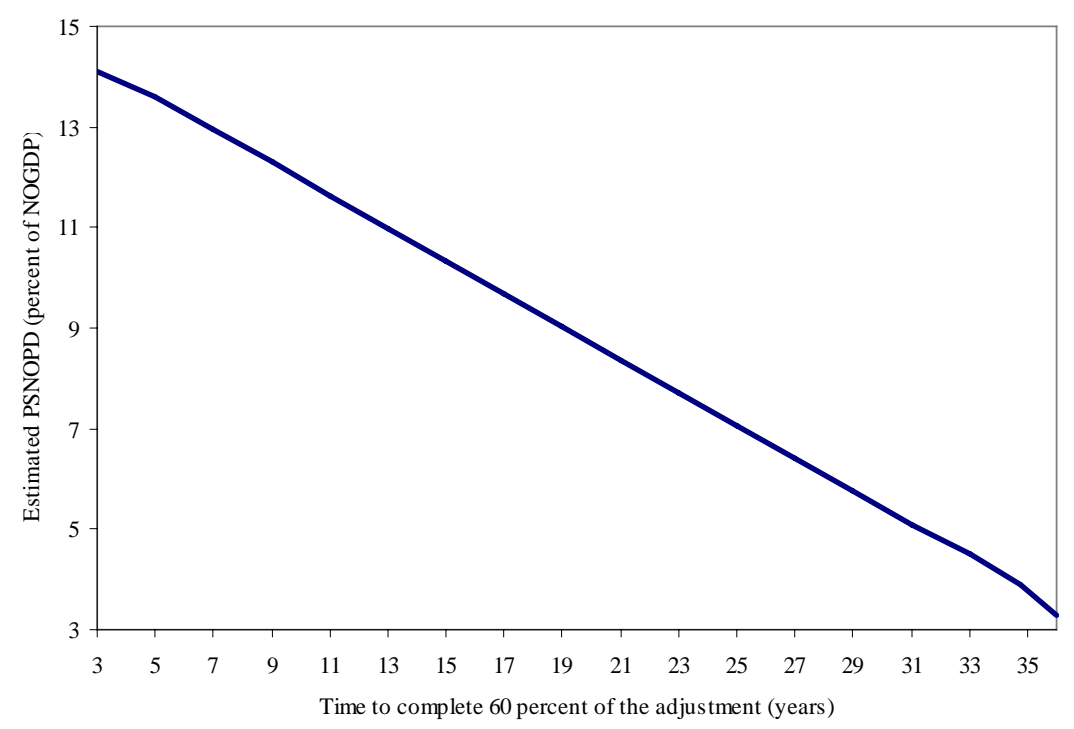

Source: IMF staff simulations.

\section{EXTENSIONS}

This section discusses extensions of the model, notably introducing uncertainty, productive public investment, and the role of public expenditure management.

\section{A. Uncertainty and Precautionary Saving Motives}

Uncertainty, as in the case of obsolescence or unpredictable oil-price fluctuations, introduces a precautionary saving motive. The impact of uncertainty on the appropriate conduct of fiscal policy depends on the degree of the government's risk aversion. The higher the degree of risk aversion, the greater the incentive of the government to build up a buffer stock of savings. ${ }^{14}$

Moreover, any analysis of public debt sustainability should explicitly acknowledge the presence of risks by simulating the effects of a number of various shocks. The standard debt sustainability analysis (DSA) typically addresses risks to the baseline debt projection by conducting simulations based on less favorable macroeconomic conditions (lower growth, higher interest rates, a lower primary balance, and exogenous debt increases, such as those resulting from exchange rate depreciation or the recognition of off budget obligations). The calibration of the shocks generally uses a multiple or fraction of the historical standard deviation of the underlying series. For OPCs, explicitly assessing the impact on fiscal

\footnotetext{
${ }^{14}$ See Barnett and Ossowski (2003) for an illustration of uncertainty in the case of obsolescence, and Carroll (2000) for a more general discussion of how to solve for the optimal spending path in the presence of unpredictable future income streams.
} 
sustainability of alternative future oil-price paths is particularly important. ${ }^{15}$ This approach was followed in section IV, which conducts simulations based on various scenarios (Table 2). Ideally, measuring risk to debt dynamics would involve a stochastic simulation framework with risk aversion that would conduct many bound tests covering a range of likely shock combinations. Celasun and others (2005) introduce a framework capable of randomly generating a large number of bound tests, and compute frequency distributions of the debt ratio. The resulting debt projection is then presented in the form of a "fan chart," permitting an explicit probabilistic assessment of debt sustainability. Celasun et al. (2005) apply this approach to five emerging market countries: Argentina, Brazil, Mexico, South Africa, and Turkey. Extending the "fan chart" approach to explicitly model oil price risks is the subject of current research.

\section{B. Productive Capital Spending}

Introducing productive government infrastructure spending into the model could, under certain conditions, justify a higher NOPD in the near-term than prescribed by standard models without productive public investment. ${ }^{16}$ For example, Takizawa, Gardner, and Ueda (2004) assess whether OPCs should spend their oil wealth upfront using a model in which public spending can, if it is of sufficient quality, influence productivity growth. They find that, if the economy starts with a capital stock that is below the steady-state level, and if the impact of government investment on growth exceeds a given quality threshold, then government spending should, in the short run, exceed the level prescribed by standard PIH models. While they do find that there is a trade-off between such higher spending in the short run and lower spending in the long run, the overall effect on social welfare is positive if the short-run impact on growth is sufficiently strong. Importantly, Takizawa, Gardner and Ueda (2004) find that if the impact of public investment on growth does not exceed the required threshold, then the standard PIH policy remains optimal.

However, given the lack of robust evidence regarding the relationship between public investment and growth, evaluating fiscal sustainability without allowing for (additional) productive public investment provides a useful benchmark. Moreover, a number of influential studies find a negative relationship between public investment and growth. For example, Sala-i-Martin and others (2004) find that the correlation between public investment and long-run growth is either negative or insignificant using a large data sample that includes both developing and developed economies. IMF (2004) conducts a sweeping survey of the growth literature, and concludes that "studies of the impact of public investment on

\footnotetext{
${ }^{15}$ See Leigh and Olters (2006) for an illustration of how alternative future oil-price paths affect the permanently sustainable NOPD.

${ }^{16}$ A caveat of the model used in this paper is that the return of public investment is not specifically modeled and is instead assumed to be embedded in the projections of economic growth taken as given for the analysis.
} 
longer-term growth do not give clear-cut results.” Finally, the ability of the government to reap the dividends of higher growth, which depend on the tax system and the quality of the tax administration, needs to be taken into account. ${ }^{17}$

\section{Public Expenditure Management Issues}

Given the importance of the quality of spending, rather than merely its level, strengthening public expenditure management should be a key element of any medium-term fiscal strategy. As Segura (2006, p. 12) notes, oil-producing countries must "think about absorptive capacity constraints - at the technical, institutional and infrastructural levels - and the need to ensure an effective tracking system to minimize wasteful public spending." ${ }^{18}$

In the context of Congo, specific measures need to be taken to (i) strengthen the institutional and absorptive capacities of the economy for higher public spending; (ii) make the public procurement system transparent and competitive; and (iii) improve the monitoring and tracking of public spending at all levels. Establishing a functional classification system for government expenditures, including poverty related expenditures, would help to assess whether public spending is in accordance with the priorities identified in the Poverty Reduction Strategy Paper (PRSP). In the context of the projected large increases in government capital expenditures over the next few years, priority should also be given to implementation of a new public investment management system to provide for rigorous selection, as well as efficient execution and monitoring, of public investment projects.

\section{Conclusion}

In assessing Congo's fiscal-policy options during the remaining years of oil production, this paper reaches four main conclusions. First, Congo's current non-oil primary deficit is not sustainable. The permanently sustainable non-oil primary deficit, estimated at about 13 percent of NOGDP, is well below the level of 29 percent of NOGDP in 2005. Second, the presence of habit formation justifies spreading the bulk of the adjustment over a number of years, rather than conducting the single, abrupt adjustment that standard permanent income models without habits prescribe. Third, there is a tradeoff between slower adjustment and a

\footnotetext{
${ }^{17}$ The relationship between public investment and growth is difficult to model and generalize, and should be looked at on a country by country basis, partly because major determinants of growth are connected to the quality of policies, institutions, and decisionmaking, and the management of exogenous shocks (IMF, 2006).

18 This is particularly true in the current context of historically high world market prices for crude oil and consequent upward pressures on the real exchange rate. Indeed, increases in the world market price of oil have affected growth of both total GDP and NOGDP through an appreciation of the real effective exchange rate (see Bhattacharya and Ghura, 2006, on Congo). Given the peg of the CFA franc to the euro, there is little that can be done directly to tackle the problem of real effective exchange rate appreciation. However, the potential negative growth effects, particularly on the non-oil sector, can be partly offset by ensuring that higher spending from oil revenue windfalls is utilized effectively to expand the productive potential of the economy, for example by developing the country's physical infrastructure and human capital.
} 
lower long-run sustainable deficit. Moreover, uncertainty regarding future economic conditions would provide a risk-averse policymaker with precautionary motives for front-loading adjustment. Finally, the quality of public expenditure should improve over time as public financial management is enhanced and an appropriate growth and povertyreduction strategy developed, providing greater assurance that government spending could generate adequate social pay-offs. 


\section{Appendix}

Figure 8. Primary Expenditure and Non-Oil Primary Balance in billion CFAF Using Two Different Welfare Criteria

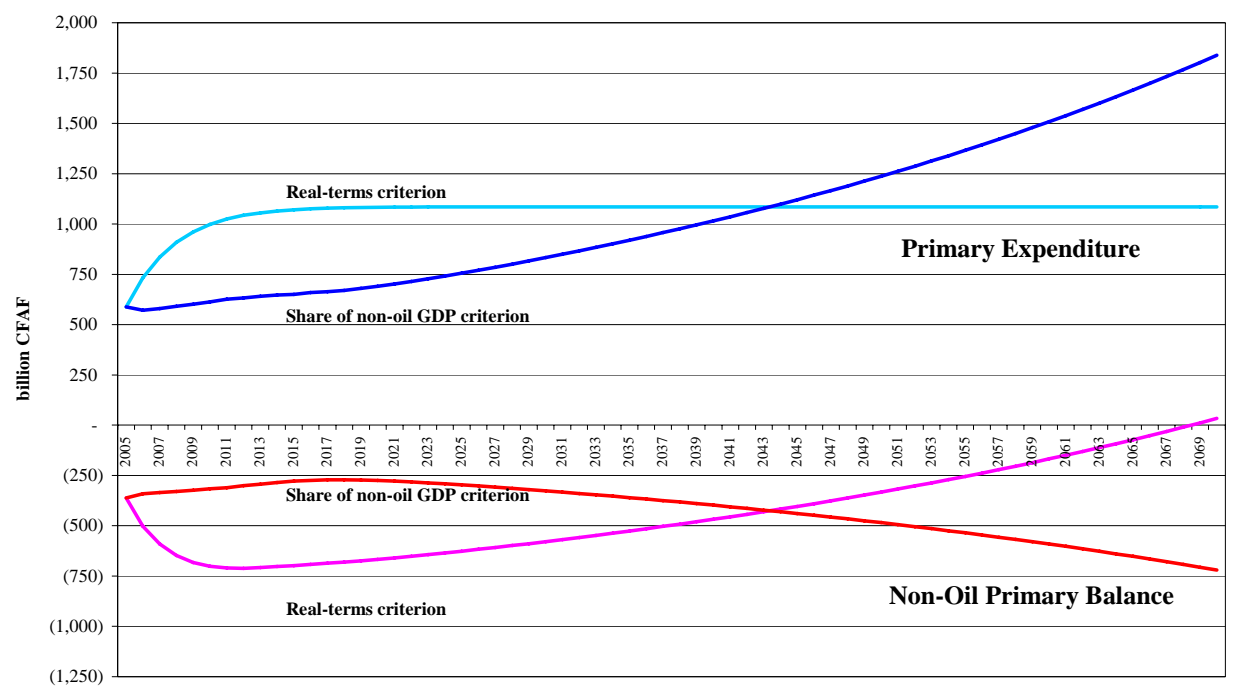

Source: IMF staff simulations.

Figure 9. Primary Expenditure and Non-Oil Primary Balance as a percentage of NOGDP Using Different Welfare Criteria

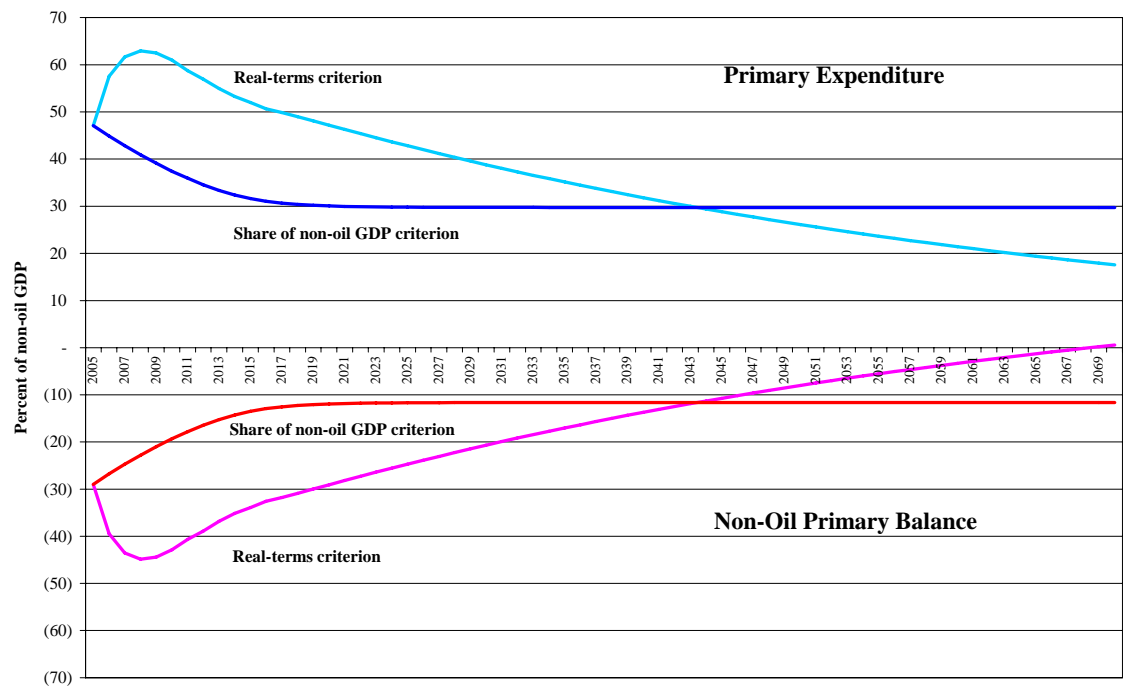

Source: IMF staff simulations. 


\section{REFERENCES}

Barnett, Steven, and Rolando Ossowski, 2003, “Operational Aspects of Fiscal Policy in Oil-Producing Countries,” in Fiscal Policy Formulation and Implementation in Oil-Producing Countries ed. by Jeffrey Davis, Rolando Ossowski, and Annalisa Fedelino (Washington: International Monetary Fund), pp. 45-81.

Bhattacharya, Rina, and Dhaneshwar Ghura, 2006, "Oil and Growth in the Republic of Congo,” forthcoming IMF Working Paper (Washington: International Monetary Fund).

Blanchard, Olivier, and Stanley Fischer, 1998, Lectures on Macroeconomics (Cambridge: MIT Press).

Carroll, Christopher, 2000, “'Risky Habits’ and the Marginal Propensity to Consume Out of Permanent Income,” International Economic Journal, Vol. 14, No. 4, pp.1-41.

Celasun, Oya, Xavier Debrun, and Jonathan David Ostry, 2005, “Primary Surplus Behavior and Risks to Fiscal Sustainability in Emerging Market Countries: A 'Fan-Chart' Approach,” IMF Working Paper 06/67 (Washington: International Monetary Fund).

Fuhrer, Jeffrey, 2000, "Habit Formation in Consumption and Its Implications for Monetary Policy Models,” American Economic Review, 90(3), pp. 367-90.

Gruber, Joseph, 2001, “Habit Formation and the Dynamics of the Current Account,” Johns Hopkins University Thesis.

International Monetary Fund, 2004, “Public Investment and Fiscal Policy,” (Washington: International Monetary Fund).

_ 2006, “Applying the Debt Sustainability Framework for Low-Income Countries Post Debt Relief,” (Washington: International Monetary Fund).

Leigh, Daniel, and Jan-Peter Olters, 2006, “Natural-Resource Depletion, Habit Formation, and Sustainable Fiscal Policy: Lessons from Gabon,” IMF Working Paper 06/193 (Washington: International Monetary Fund).

Obstfeld, Maurice, and Kenneth Rogoff, 1996, Foundations of International Macroeconomics, (Cambridge: MIT Press).

Sala-i-Martin, Xavier, and Arvind Subramanian, 2003, “Addressing the Natural Resource Curse: An Illustration from Nigeria”, IMF Working Paper 03/139 (Washington: International Monetary Fund).

Segura, Alonso, 2006, “Management of Oil Wealth Under the Permanent Income Hypothesis: The Case of São Tomé and Príncipe,” IMF Working Paper 06/183 (Washington: International Monetary Fund). 
Takizawa, Hajime, Edward Gardner, and Kenichi Ueda, 2004, “Are Developing Countries Better Off Spending Their Oil Wealth Upfront?” IMF Working Paper 04/141 (Washington: International Monetary Fund).

Tersman, Gunnar, 1991, “Oil, National Wealth, and Current and Future Consumption Possibilities,” IMF Working Paper 91/60 (Washington: International Monetary Fund).

Velculescu, Delia, 2004, “Intergenerational Habits, Fiscal Policy, and Welfare,” Topics in Macroeconomics, Volume 4, No. 1, The Berkeley Electronic Press. Available via the Internet: http://www. bepress.com/bejm/topics/vol4/iss1/art10 